\begin{tabular}{|c|c|}
\hline Title & $\begin{array}{l}\text { Spontaneous mosaicism occurred in normally fertilized and gynogenetically induced progeny of the kokanee sal mon } \\
\text { Oncorhynchus nerka }\end{array}$ \\
\hline Author(s) & Tanaka, Minoru; Kimura, Shizuo; Fujimoto, Takafumi; Sakao, Suzu; Y amaha, Etsuro; A rai, Katsutoshi \\
\hline Citation & $\begin{array}{l}\text { Fisheries Science, 69(1), 176-180 } \\
\text { https://doi.org/10.1046/.1444.2906.2003.00603.x }\end{array}$ \\
\hline Issue Date & 2003 \\
\hline DOC URL & http:/hdl.handle.net/2115/35205 \\
\hline Rights & ○ 2003 公益社団法人日本水産学会; @ 2003The Japanese Society of Fisheries Science \\
\hline Type & article \\
\hline File Information & arai-75.pdf \\
\hline
\end{tabular}

Instructions for use 


\title{
Spontaneous mosaicism occurred in normally fertilized and gynogenetically induced progeny of the kokanee salmon Oncorhynchus nerka
}

\author{
Minoru TANAKA, ${ }^{1}$ Shizuo KIMURA, ${ }^{2}$ TaKafumi FUJIMOTO,${ }^{1}$ Suzu SAKAO, ${ }^{1}$ Etsuro YAMAHA ${ }^{2}$ \\ AND KATSUTOSHI ARAI ${ }^{1, *}$ \\ ${ }^{1}$ Laboratory of Breeding Science, Graduate School of Fisheries Sciences, Hokkaido University, \\ Hakodate, Hokkaido 041-8611 and ${ }^{2}$ Nanae Fresh Water Laboratory, Field Science Center for \\ Northern Biosphere, Hokkaido University, Nanae, Hokkaido 041-1105, Japan
}

\begin{abstract}
In normally fertilized progeny of the kokanee salmon Oncorhynchus nerka, DNA content flow cytometry revealed that all the externally normal embryos were diploid, whereas abnormal embryos exhibited haplo-diploid, diplo-tetraploid and haplo-diplo-tetraploid mosaicisms, together with a few haploid and diploid individuals. When gynogenetic development was artificially induced by fertilization of eggs obtained from a female of the same kokanee brood stock with UV-irradiated sperm, haplo-diploid mosaics appeared most frequently. These mosaics were likely to happen by certain cytological events, such as meiotic or mitotic errors during the process of maturation, fertilization or early cleavage.
\end{abstract}

KEY WORDS: DNA content, gynogenesis, mosaic, polyploid.

\section{INTRODUCTION}

A mosaic is an individual with two or more distinct genotypes despite its development from a single fertilized egg or zygote. ${ }^{1}$ Polyploid mosaics, such as haplo-diploid, diplo-triploid and other unusual cytotypes, have two or more kinds of cell populations possessing different ploidy status within an individual. In fish and other aquatic animals, such a mosaicism has been recognized as a relatively rare phenomenon, because it was difficult practically to detect two or more cytotypes by means of conventional chromosome observations and cell measurements, both of which required much labor and time for ploidy determination. ${ }^{2}$ However, recent prevalence of flow cytometry techniques makes it easier to determine a mosaic individual with different polyploid cells. ${ }^{2}$

Flow cytometry has been applied to evaluate the success of chromosome manipulation in aquaculture species and has often detected the occurrence of mosaicism, probably due to inappropriate treat-

\footnotetext{
*Corresponding author: Tel. 81-138-40-5535.

Fax: 81-138-40-5537. Email: araikt@fish.hokudai.ac.jp

Received 15 May 2002. Accepted 12 September 2002.
}

ments in chromosome manipulation. ${ }^{2}$ Although survivors from the inhibition of the first cleavage with hydrostatic pressure shock after normal fertilization have been predicted to be tetraploid, Yamaki et $_{\text {al. }}{ }^{3,4}$ found a few diplo-tetraploid mosaics together with a large number of misinduced diploids in such treated groups of amago salmon Oncorhynchus masou ishikawae. Production of triploid progeny was also reported in the cross between a diplo-tetraploid mosaic female and a normal male. ${ }^{4}$ In gynogenetically reproducing triploid crucian carp Carassius langsdorfii, triplotetraploid mosaics appeared after cold and heatshock treatments of fertilized eggs, probably due to the delayed pronucleation of sperm nucleus and subsequent syngamy with blastomere nucleus at the cleavage stage after the initiation of gynogenetic embryogenesis. ${ }^{5}$

In normally cultured population of the charr, Salvelinus leucomaenis, a live haplo-diploid mosaic individual in which approximately $90 \%$ of blood, liver and spleen were haploid, but most brain cells were diploid, was found and then flowcytometrically confirmed. ${ }^{6}$ In wild populations of the loach Misgurnus anguillicaudatus, diplotriploid mosaic individuals were detected together with spontaneous triploid and clonally reproducing diploid individuals. ${ }^{7,8}$ Spontaneous diplo- 
triploid individuals were also reported in a hybrid origin minnow species Phoxinus eos-neogaeus, which includes triploid and clonal diploid individuals. ${ }^{9}$ These examples suggest that many more mosaicisms awaiting discovery may be present both in normally cultured and chromosomally manipulated populations of fish species. At present, however, little is known about the mosaicisms in fish species due to the shortage of studies.

To disclose the presence or absence of polyploid mosaicism and other similar cytogenetic event especially in aquaculture fish species, we examined ploidy status of both externally normal and abnormal embryos developing from fertilized eggs of the kokanee salmon Oncorhynchus nerka by measuring DNA content of embryonic cells with flow cytometry. We also examined the expression of mosaicism in the progeny of the gynogenetically activated eggs.

\section{MATERIALS AND METHODS}

\section{Fish specimens}

Kokanee salmon Oncorhynchus nerka have been propagated and cultured in the Nanae Fresh Water Laboratory, Field Science Center for Northern Biosphere, Hokkaido University, since 1993 when this strain was transferred from the Chitose branch of the Hokkaido Salmon Hatchery, Ministry of Agriculture, Forestry and Fisheries, to the Nanae Fresh Water Laboratory.

\section{Normal fertilization}

On 7 October 1999, artificial fertilization was performed between spontaneously ovulated eggs from six females and pooled sperm from three mature males. On 17 October 2001, eggs pooled from two females were fertilized with sperm pooled from three males. Fertilization was completed by adding Ringer solution, ${ }^{10}$ followed by the activation of the eggs with fresh water. Fertilized eggs were kept in an incubation chamber for about 40 days at $10^{\circ} \mathrm{C}$ water temperature.

At the hatching stage in 1999 and eyed embryos in 2001, chorion was artificially removed. Externally abnormal embryos were sorted by observation with the naked eye. Yolk sacs of abnormal embryos were broken at the artificial removal of chorion, because of structural weakness. Both abnormal and normal control samples were photographed and their ploidy status was estimated by measuring nuclear DNA content with flow cytometry as described below.

\section{Induced gynogenesis}

On 18 October 1999, haploid gynogenesis was induced by activating eggs from one female of the same brood stock with UV irradiated, genetically inert sperm. UV irradiation of sperm was performed according to Onozato and Yamaha ${ }^{11}$ with slight modifications. Briefly, sperm collected from four males were diluted about 50 -fold by seminal plasma collected from masu salmon $O$. masou milt by centrifugation. Diluted milt was spread on the bottom of a plastic Petri dish with hydrophilic pretreatment by ion-sputtering equipment and irradiated with UV rays at $4800 \mathrm{erg} / \mathrm{mm}^{2}$ dose. UVirradiated sperm were collected into glass tubes and then used to inseminate mature eggs. Control cross was also performed by fertilizing eggs with non-irradiated sperm. All the progeny were incubated at $10^{\circ} \mathrm{C}$ water temperature.

\section{Ploidy determination}

Whole body of each embryo was immersed in a 1.5-mL microfuge tube containing $1 \mathrm{~mL}$ prechilled $\left(4^{\circ} \mathrm{C}\right)$ Eagle minimum essential medium (MEM) and then minced. A small part of the homogenate was suspended into the medium by gentle shaking and pipetting. Suspended cells were stained with 4-6-diamidino-2-phenylindole dihydrochloride (DAPI) according to the protocol provided by the manufacturer of the flow cytometer (Partec $\mathrm{GmbH}$, Münster, Germany).

Prepared samples were examined for DNA content of cell nucleus by the flow cytometer (Ploidy Analyzer, Partec GmbH, Germany). The ploidy status was determined by comparing relative DNA content measured. When the DNA content of the erythrocytic cells of the normal diploid specimens was expressed as $2 \mathrm{C}$, the triploid was determined by about 3C DNA content.

\section{RESULTS}

\section{Mosaics occurred in normally fertilized progeny}

As shown in Table 1, all the externally normal embryos examined in normally fertilized eggs of the 1999 group (Fig. 1a, $n=30$ ) were diploid, judging from the DNA content measured by flow cytometry (Fig. 2a). In contrast, abnormal embryos sorted from the normally fertilized group $(n=37)$ exhibited frequent mosaicism (Fig. 1b; Table 1). Haplo-diploid (Fig. 2d, 5.4\%, 2/37), diplotetraploid (Fig. 2c, 81.1\%, 30/37) and haplo-diplotetraploid mosaics (Fig. 2e, 8.1\%, 3/37) were 
Table 1 Ploidy status and external appearance of embryos developing from normally fertilized eggs of the kokanee salmon

\begin{tabular}{llcccccc}
\hline \multirow{2}{*}{$\begin{array}{l}\text { Breeding } \\
\text { year }\end{array}$} & $\begin{array}{c}\text { External } \\
\text { appearance }\end{array}$ & $\begin{array}{c}\text { Embryo } \\
\text { no. }\end{array}$ & 1n & $2 \mathrm{n}$ & $1 \mathrm{n} / 2 \mathrm{n}$ & $2 \mathrm{n} / 4 \mathrm{n}$ & $\ln / 2 \mathrm{n} / 4 \mathrm{n}$ \\
\hline 1999 & Normal & 30 & 0 & 30 & 0 & 0 & 0 \\
& Abnormal & 37 & 1 & 1 & 2 & 30 & 3 \\
2001 & Normal & 5 & 0 & 5 & 0 & 0 & 0 \\
& Abnormal & 3 & 0 & 0 & 0 & 3 & 0 \\
\hline
\end{tabular}

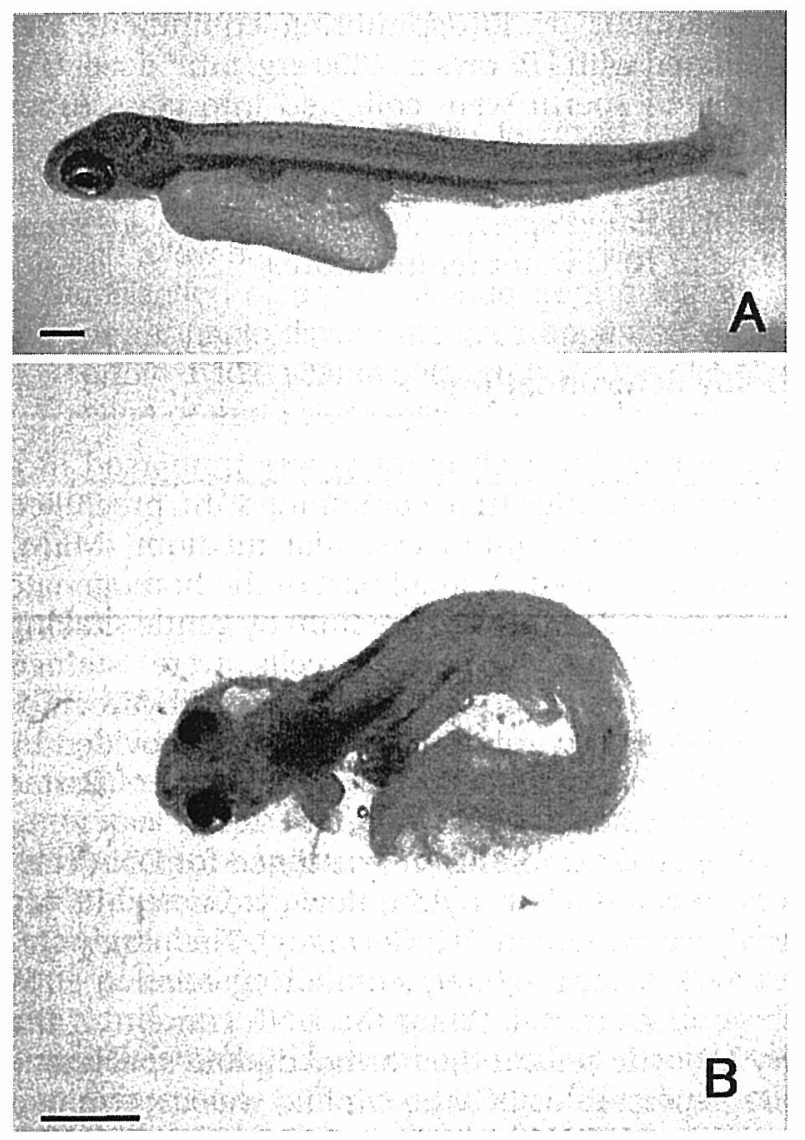

Fig. 1 (a) Normal and (b) abnormal kokanee salmon alevin developing from normally fertilized eggs. Scale indicates $1 \mathrm{~mm}$.

detected in these abnormal embryos. Besides mosaics, one haploid (Fig. 2b) and one diploid were also found. Almost all the mosaic embryos detected were mainly characterized with microcephaly and/or microphthalmia (Fig. lb). These abnormalities observed in mosaic embryos were similar to those collectively referred to as haploid syndrome. The ratio between diploid and tetraploid cells was estimated from the area of histograms in the flow cytometry of diplo-tetraploid mosaics and an approximately 2:1 ratio (diploid: tetraploid $=45-56: 23-28$ ) was seen in all these mosaics (Fig. 2).

Spontaneous mosaicism was checked again in normal fertilized eggs for the same brood stock in 2001. Three abnormal embryos were sorted from approximately 3000 eyed eggs developing from normal fertilization in the 2001 experiment. These embryos were characterized with microcephaly as well as microphthalmia and were determined as diplo-tetraploid mosaic comprising diploid and tetraploid cells in an approximately $2: 1$ ratio (diploid : tetraploid $=51-56: 23-28$ ).

\section{Mosaics occurred in gynogenetic progeny}

Developing capacity and ploidy status of the gynogenetic kokanee are shown in Table 2 . Fertility was $63.6 \%$ in the gynogenesis, but $82.7 \%$ in the control. Developing rates of 22-day-old embryos were $65 \%$ and $81 \%$ in control and induced gynogenesis, respectively. Most control embryos (92.3\%) were normal diploid, but one diplo-tetraploid $(7.7 \%)$ with morphological abnormalities was detected (Table 2). Gynogenetic embryos induced by fertilizing eggs with UV-irradiated sperm showed not only haploid (35.3\%), but also haplo-diploid mosaic (64.7\%). All the embryos developing from the induced gynogenesis were externally abnormal.

\section{DISCUSSION}

In kokanee alevins hatching from normally fertilized eggs in the 1999 experiment, normal ones were diploid, whereas almost all the abnormal alevins were haplo-diploid, diplo-tetraploid or haplo-diplo-tetraploid mosaics. Among them, diplo-tetraploid was the most frequent. Only diplotetraploid mosaics were found in abnormal alevins in the 2001 experiment. These results suggest a tight correlation between morphological abnormality and mosaicism. However, mosaicism is unlikely to be a direct cause of the abnormal devel- 

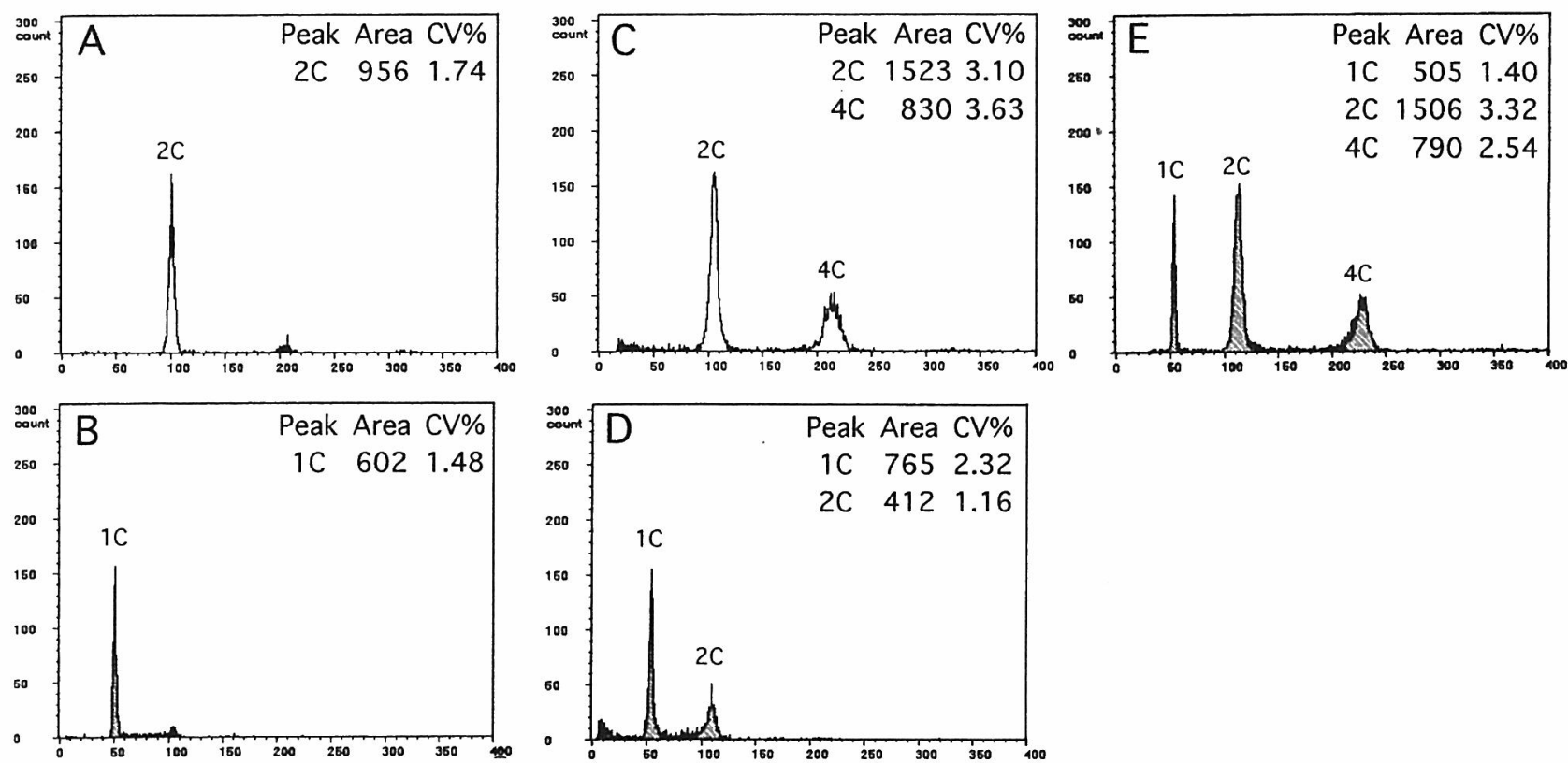

Fig. 2 DNA content of embryonic cells of (a) normal and (b-e) abnormal kokanee embryos measured by flow cytometry. (a) Diploid, (b) haploid, (c) diplo-tetraploid, (d) haplo-diploid, (e) haplo-diplo-tetraploid.

Table 2 Ploidy status and dvelopment capacity of control and gynogenetic progeny of the kokanee salmon

\begin{tabular}{|c|c|c|c|c|c|c|c|c|}
\hline \multirow[b]{2}{*}{ Experiment } & \multirow{2}{*}{$\begin{array}{l}\text { Egg } \\
\text { no. }\end{array}$} & \multirow{2}{*}{$\begin{array}{c}\text { Fertility } \\
(\%)\end{array}$} & \multirow{2}{*}{$\begin{array}{l}22 \text {-day-old } \\
\text { embryo no. }\end{array}$} & \multirow{2}{*}{$\begin{array}{l}\text { Developing } \\
\text { rate }(\%)^{*}\end{array}$} & \multirow{2}{*}{$\frac{\text { Normal }}{2 \mathrm{n}}$} & \multicolumn{3}{|c|}{ Abnormal } \\
\hline & & & & & & $\ln$ & $\ln / 2 n$ & $2 n / 4 n$ \\
\hline Control & 20 & 82.7 & 13 & 65 & 12 & 0 & 0 & 1 \\
\hline Gynogenesis & 42 & 63.6 & 34 & 81 & 0 & 12 & 22 & 0 \\
\hline
\end{tabular}

*Developing rate indicates percentage of developed embryos in the total number of eggs used.

opment, because the diplo-tetraploid amago salmon were reported to be normal and viable. ${ }^{3,4}$ Live mosaics have been detected in wild populations of the loach $^{7,8}$ and the minnow. ${ }^{10}$ Thus, the mosaicism itself is not a cause of abnormality, but a result of a certain cytological' event.

Mosaics were also detected when the kokanee eggs were activated with UV-irradiated sperm to induce artificial gynogenesis in the present study. Although only haploid embryos were predicted in the artificial gynogenetic progeny, about $65 \%$ of embryos were haplo-diploid mosaics when the breeding was performed using the kokanee female of the same broodstock in 1999. The occurrence of haplo-diploids in gynogenesis as well as diplotetraploids in normal fertilization suggests that the mosaicism should not be due to the sperm, but to the eggs used. These mosaicisms are likely to happen by a mitotic error such as spontaneous endomitosis (chromosome duplication without cytokinesis) occurring in one blastomere in the two-cell or the later multi-cell-stage embryos. In this case, both diploid and tetraploid cells would occur in normally fertilized zygotes and both haploid and diploid cells in gynogenetic embryos. Meiotic error, such as karyogamy between female and male pronucleus, followed by independent development of haploid polar body leading to generation of both haploid and diploid cell populations, cannot explain the haplo-diploidy that occurred in the gynogenetic progeny, but those appeared in the normally fertilized group. This type of meiotic error has been considered a major cause of haplo-diploid mosaicism in the salmonids. ${ }^{12}$ The occurrence of haplo-diplo-tetraploid mosaics can be explained by the spontaneous endomitosis in a blastomere after the development of haplo-diploid embryos probably produced by the meiotic error. However, the polyspermy, which is the most likely origin of haploid cells in the mosaic chicken Gallus domesticus ${ }^{13}$ cannot be ruled out as the cause of the haplodiploid mosaics that appeared in the normally fertilized group of the kokanee salmon. In this 
case, additional sperm nucleus might initiate independent development as a haploid cell.

In the gynogenetic kokanee progeny produced by fertilization with UV-irradiated sperm, all the haplo-diploid mosaics were morphologically abnormal like haploid embryos characterized with so-called haploid syndrome. The present result is inconsistent with previous results reported in charr, ${ }^{6}$ chicken ${ }^{13}$ and toad, ${ }^{14}$ that showed drastic improvement of poor survival rates of haploid embryos by adding diploid or triploid organs, tissues and cells. In frog, such a rescuing effect of additional diploid cells has been confirmed by longitudinal haploid-diploid chimeras produced by an experimental embryological procedure. ${ }^{15}$ As the percentage and distribution of haploid cells in each organ were not examined in the haplo-diploid mosaic kokanee embryos, the possibility cannot be excluded that the diploid cells did not have enough prophylatic effect in the haplo-diploid kokanee, due to inappropriate ratio and spatial distribution of diploid cells in each mosaic. In the present study, high frequencies of unpredictable mosaic individuals were detected in the kokanee progeny. Correlation between frequent occurrence of mosaicism and genetic factors has been suggested in the chicken, because certain chicken strains have shown significantly high frequencies of abnormal cytological events, including mosaicism. ${ }^{12}$ Thus, the genetic background of frequent mosaicisms should be examined in the brood stock of farmed kokanee salmon and other salmonid populations in the near future, from the viewpoint of the involvement of inbreeding and subsequent expression of deleterious recessive genes. The other actual cause of mosaicism may be egg quality. Yamazak ${ }^{16}$ reported the occurrence of chromosome aberration including haploidy, aneuploidy, triploidy and haplo-diploid mosaicism, due to aging and/or the over-ripening of ovulated rainbow trout Oncorhynchus mykiss eggs. More detailed studies are required to disclose the correlation between egg quality and the mosaicisms.

\section{ACKNOWLEDGMENTS}

This work was supported in part by a Grant-in-Aid for scientific research (B) from Japan Society for the Promotion of Science (JSPS) to KA (No. 13460079) and the Akiyama Foundation in 2000 to KA.

\section{REFERENCES}

1. King RC, Stansfield WD. A Dictionary of Genetics, 4th edn. Oxford University Press, Oxford. 1990.

2. Arai K. Genetic improvement of aquaculture finfish species by chromosome manipulation techniques in Japan. Aquaculture 2001; 197: 205-228.

3. Yamaki M, Satou M, Satou H, Kon Y, Zhang Q, Uchimura Y. Induction of tetraploid amago salmon by hydrostatic pressure and heat shocks and its verification by the maximum number of nucleoli and DNA contents. Fish Genet. Breed. Sci. (Suisan-Ikushu) 1997; 25: 37-48.

4. Yamaki M, Satou H, Taniura K, Arai K. Progeny of diploidtetraploid mosaic amago salmon. Nippon Suisan Gakkaishi 1999; 65: 1084-1089.

5. Mada Y, Miyagawa M, Hayashi T, Umino T, Arai K. Production of tetraploids by induction of sperm nucleus into the eggs of gynogenetic triploid ginbuna Carassius langsdorfii. Suisanzoshoku 2001; 49: 103-112.

6. Yamaki M, Kawakami K, Taniura K, Arai K. Live haploiddiploid mosaic charr Salvelinus leucomaenis. Fish. Sci. 1999; 65: 736-741.

7. Zhang Q, Arai K. Distribution and reproductive capacity of natural triploid individuals and occurrence of unreduced eggs as a cause of polyploidization in the loach, Misgurnus anguillicaudatus. Ichthyol. Res. 1999; 46: 153-161.

8. Morishima K, Horie S, Yamaha E, Arai K. A cryptic clonal line of the loach Misgurnus anguillicaudatus (Teleostei: Cobitidae) evidenced by induced gynogenesis, interspecific hybridization, microsatellite genotyping and multilocus DNA fingerprinting. Zool. Sci. 2002; 19: 565-575.

9. Dawley RM, Goddard KA. Diploid-tetraploid mosaics among unisexual hybrids of the minnow Phoxinus eosneogaeus. Evolution 1988; 42: 649-659.

10. Yamamoto TS. Fertilization of dog salmon eggs in Ringer's solution. J. Fac. Sci. Hokkaido Univ., Ser. VI Zool. 1976; 20: 159-166.

11. Onozato H, Yamaha E. Induction of gynogenesis with ultraviolet rays in four species of salmoniformes. Nippon Suisan Gakkaishi 1983; 49: 693-699.

12. Miller GD, Seeb JE, Bue BG, Sharr S. Saltwater exposure at fertilization induces ploidy alterations, including mosaicism, in salmonids. Can. J. Fish. Aquat. Sci. 1994; 51: 4249.

13. Thorne MH, Collins RK, Sheldon BL. Live haploid-diploid and other unusual mosaic chickens (Gallus domesticus). Cytogenet. Cell Genet. 1987; 45: 21-25.

14. Muto Y. Haploid-triploid mosaic toads induced by heattreatment of the unfertilized eggs. J. Sci. Hiroshima Univ. 1951; 12: 39-46.

15. Kashiwagi K, Kashiwagi A. Artificially produced chimeras between haploids and diploids in Japanese anurans. Sci. Report Laboratory Amhibian Biol. Hiroshima Univ. 1993; 12: 37-53.

16. Yamazaki F. Sex control and manipulation in fish. Aquaculture 1983; 33: 329-354. 